\title{
Down's syndrome screening: a controversial test, with more controversy to come!
}

\author{
T M Reynolds
}

\begin{abstract}
By 1998, most health authorities offered antenatal screening for Down's syndrome, usually by biochemical methods. To date, the development of this form of screening has not been coordinated by a national body and, consequently, there are wide variations in practice between localities. Fortunately, many of these variations have not led to any noticeable inequality of health provision, but the wide variation in risk cut offs used by different centres does. Other variations merely lead to potentially unnecessary expenditure; whereas it is believed that adding extra tests to the screening procedure is beneficial (such as double test to triple test), statistical evaluation of the confidence intervals for the detection rates quoted indicates that there is no evidence that the extra test provides an increase in detection. The cervical screening programme has progressively improved, partly through the auspices of a
\end{abstract} national framework. A similar national approach would benefit Down's screening and is only now being considered: the national screening committee (NSC) is currently drafting recommendations. To ensure optimum screening performance, the NSC should specify the risk thresholds applied, the screening protocols to be used-that is, an opt-in programme with a minimum (possibly even a maximum) of two biochemical analytes or a nuchal fold evaluation-and perhaps should even recommend national population parameters to be used for risk calculation. It might even be advisable for statistical work to be carried out to determine whether local derivation of medians is truly necessary. Furthermore, defined options for older women could be specified-for example, should all older patients have the option to proceed directly to amniocentesis if they wish or should National Health Service amniocentesis only be available for those with a "high risk" screening result. The difficulties that will face the NSC in deciding which screening policy to adopt are also considered; specifically, the lack of evidence to suggest that triple testing is superior to double testing, and the lack of evidence to prove the superiority of one analyte over another. This inadequacy of evidence is not from want of trying, but is caused by the problems of collecting enough data to provide statistical significance. Finally, there is one important difference between cervical and Down's syndrome screening that has a major impact on the advice given by any "expert"; namely, patents. Many aspects of Down's screening are subject to patents and, therefore, there is more potential for apparently uncontroversial decisions to rebound with future retrospective patent infringement claims. Thus, it would be sensible to insist that any member of a national body deciding upon Down's screening policy must fully disclose all potential conflicts of interest, both personal and family, before they are allowed to sit on the committee. Furthermore, if a national policy is decided upon, worldwide patent searches should be carried out to determine whether there are any possible unforeseen legal consequences of any recommendation.

(F Clin Pathol 2000;53:893-898)

Keywords: trisomy 21; screening; nuchal fold

Down's syndrome screening became feasible in 1988 when the seminal paper on the subject was published. ${ }^{1}$ The first routine National Health Service (NHS) Down's syndrome screening programme using biochemical markers began in February 1990 in Newport and Cardiff. This was initially run as a one year prospective trial, which demonstrated that screening was acceptable to both doctors and the local population. ${ }^{2}$ By 1998, $72 \%$ of UK health authorities offered serum screening for all women, $10 \%$ offered age restricted serum screening, and only $8 \%$ restricted screening to age alone. Most of those offering biochemical screening use just two markers ( $\alpha$ fetoprotein (AFP) and either total or free human chorionic gonadotrophin ( $\beta-\mathrm{HCG})$ ). Nuchal fold screening was provided by $7 \%$ of health authorities to women of any age. ${ }^{3}$

Dutch researchers have recently called for all pregnant women to be offered screening for Down's syndrome in the first trimester of pregnancy using a combination of maternal age, ultrasound, and biochemical markers. Currently, the only legal method for Down's screening in the Netherlands is maternal age. ${ }^{4}$ However, serum screening has been available in the Netherlands for many years, despite government disapproval, although not reimbursed by the health care system. ${ }^{5}$ Pressure for change has come from a publication of the Amsterdam Medical Centre's screening results, suggesting an $85 \%$ detection rate for a $5 \%$ false positive rate. ${ }^{6}$ In the UK, there has been little government pronouncement on the issue of Down's screening. 
Since its inception, Down's screening has been controversial. This is primarily because pregnancy is a very common condition and a child with Down's syndrome is seen as a disaster by many potential parents. The frequency of pregnancy means that the test has to be carried out on a very large number of people. Consequently, there is a large market for reagents and even a small profit margin can net a large income, in several different ways. Furthermore, the impact on parents means that Down's screening is one of the few situations where failure of a midwife to collect a sample, or failure of the sample to arrive at the laboratory, can and has resulted in litigation in which the screening laboratory has been the defendant for others' negligence.

\section{Patents}

Recently, the Biomedical Patent Management Association filed a patent infringement suit and retrospectively demanded $\$ 5$ for every Down's syndrome screening test that had been carried out in the USA using HCG (the patent did not apply in the UK). The state of California alone had screened 12 million women at this time and the ongoing additional cost to their screening programme would be $\$ 1.7$ million/ year. ${ }^{7}$ At the same time, it was asked whether the possession of patents affected the impartiality of persons promoting various screening modalities, with the suggestion that patent holding without clear declaration is unethical. Indeed, concern about such commercialism was expressed almost from the very beginning of Down's screening. ${ }^{8}$

\section{Software and population parameters}

Recently, it was reported that there had been a computer problem at a Sheffield laboratory, which had resulted in several patients being given incorrect Down's risk assessments. Software has provided great problems for Down's screening. There are several commercial software packages available, most of which perform their function extremely adequately, but most have the disadvantage that they are stand alone packages, not integrated with the main laboratory computer. This not only leads to extra expense in terms of hardware but also to a potential for data loss because, despite exhortations to the contrary, stand alone PCs are rarely backed up as assiduously as they should be. A further problem is that such software is often a "black box" and users rarely understand how the results are generated. Consequently, when the National External Quality Assessment Scheme (NEQAS) sent MoM (multiple of the median) results on dummy patients for Down's syndrome risk calculation to participating laboratories, the coefficient of variation of the estimated risks was $36.5 \%$ for double screening with AFP and total HCG, $31.5 \%$ for double screening with AFP and free $\beta-\mathrm{HCG}$, and $55.6 \%$ for triple screening with AFP, HCG, and unconjugated oestriol (uE3). ${ }^{9}$ These variations were sufficient to change the estimate of risk from clearly indicating amniocentesis to clearly precluding amniocentesis, simply as a result of software variation. Much of this variation is likely to result from different embedded population parameters in the software.

The difficulty with population parameters extends further than just the ability to alter values recorded in software. There is a multiplicity of different population parameters available, but no one can be sure which parameters should be applied to their population. There are several schools of thought. Essentially, some believe only locally derived population data should be applied, which leads to extreme difficulties in deriving local Down's syndrome population parameters, whereas others believe that published population parameters are acceptable. Herein lies another problem: there are many different sets of population parameters available; which should one use? Furthermore, the decision on screening parameters can be affected by commercial interests because if the parameters published for one analyte are given incorrectly, these can falsely improve the apparent performance of another analyte and indicate that extra screening tests must be added. ${ }^{10}$ In the case of one analyte, the failure of presentation of important data in a publication was also queried. ${ }^{11}{ }^{12}$

\section{Analytes: which and how many?}

This is another very controversial area. As stated above, most screening laboratories use a double test because AFP alone is only marginally effective; some add a third analyte, uE3, and still fewer add a fourth analyte, inhibin A. ${ }^{3}$ In the past, up to five analytes in a single screen have been suggested. ${ }^{13}$ The arguments for increasing the number of analytes always hinge upon gains in detection rate, with no increase in false positive rate, which can then be used in cost effectiveness analyses to justify the extra expense of the third assay. ${ }^{13-23}$ The evidence against adding a third analyte, which includes results published by the manufacturer of the first second trimester optimised uE3 assay (other $\mathrm{uE} 3$ assay kits are now available), either shows no increase in detection or a loss of detection, ${ }^{24-32}$ or questions the validity of the assay. ${ }^{33}$ Furthermore, some researchers have reported evidence in favour of the use of $\mathrm{uE} 3$ in one study ${ }^{16}$ but against it in another. ${ }^{27}$

Why should there be such a major split in the literature about such a fundamental question? The simple answer could be that the difference in performance is close to zero, but that each individual study is too small for any observed differences to be significant. Most studies describe no more than 100 cases of Down's syndrome. With minor variation for maternal age distribution, the SD of the detection rate, assuming a fixed $5 \%$ false positive rate, can be estimated as $38.9 / \sqrt{\mathrm{N}}$ for a triple test and as $34.8 / \sqrt{\mathrm{N}}$ for a double test. ${ }^{34}$ For example, for a study containing 20 Down's cases with a detection rate of $67 \%$, the SD of a triple test detection rate would be $38.9 / \sqrt{20}=8.7 \%$, giving rise to an approximate $95 \%$ confidence interval of $67 \% \pm 2 \times 8.7 \%$ or $49.6 \%$ to $84.4 \%$. Because most studies estimate benefits of only a few per cent, it is clear that despite the large 
number of studies carried out, there is in fact no evidence that triple testing is superior to double testing because in every study the overlap of confidence intervals is so great that there is no true statistical difference between the detection rates in the different arms of the study! Studies that claim to show a benefit from adding a fourth analyte are similarly inconclusive.

The next area of controversy is whether free $\beta$-HCG is superior to total HCG. There is a large literature suggesting that it does achieve a higher detection rate, ${ }^{11}{ }^{29}{ }^{35-39}$ with some dissenting voices. ${ }^{23} 40-44$ Others have identified problems of monoclonal antibody specificity measuring different variants (nicked and nonnicked) of free $\beta-\mathrm{HCG},{ }^{45}$ and have queried the validity of free $\beta$-HCG results because of sample instability. ${ }^{46-51}$ In common with the difference between a double and a triple test, all studies demonstrating the benefit of free $\beta-H C G$ have been small. Therefore, there is once again no evidence that free $\beta-\mathrm{HCG}$ is significantly superior to total HCG.

Notwithstanding the worries about free $\beta$-HCG sample instability, this lack of clear evidence either way for free $\beta-\mathrm{HCG}$ or total HCG probably explains the split between laboratories found in Wald's survey. ${ }^{3}$ Several of the random access immunoanalysers (for example, Abbott AxSym, Bayer Immuno1, Chiron ACS) carry out total HCG assays, whereas others (for example, Wallac DELFIA) carry out free $\beta$-HCG assays. The choice of Down's syndrome screening assay is thus influenced by the department's other immunoassay needs, rather than by any specific Down's syndrome screening related imperative. The choice to use more than two analytes is also governed more by resource availability than by scientific concerns. However, in the current financial situation, the NHS should consider seriously whether the evidence available warrants the extra spending on more than two assays for second trimester Down's screening. This should be considered urgently by the National Screening Committee (NSC).

When should screening be done: chemistry $v$ ultrasound or both?

Currently, most Down's screening takes place in the second trimester using biochemical markers. The next big debate in respect of Down's screening is when the test should be carried out and how: biochemically, ultrasonographically, or by both modalities. It has also been suggested that testing should be carried out in both the first and second trimesters, with results being imparted after the second trimester result. ${ }^{52}$ This approach has been criticised ethically and scientifically,,$^{53}$ but is too recent for its impact to be identified.

First, let us assume that first trimester testing is better for the patient and consider the potential markers. The most effective first trimester biochemical markers appear to be free $\beta$-HCG and pregnancy associated plasma protein A (PAPP-A), but other substances such as dimeric inhibin A have also been shown to be markers. ${ }^{55-66}$ However, some data suggest that this is only a weak marker in the first trimester and is better in the second. ${ }^{67}$ The other available marker is nuchal fold translucency, an ultrasonographically measured parameter that can be used without biochemistry to assess the risk of trisomy. ${ }^{68}$

If nuchal translucency alone could be used as a screening test, it would offer immediate superiority to biochemical screening because the measurement, risk calculation, and result presentation could all be carried out in a single session. However, the UK multicentre project ${ }^{68}$ demonstrating the "superiority" of nuchal fold screening had a major flaw: it was an interventional study-if an anomaly was identified action was taken. Consequently, the $80 \%$ detection rate presented in the paper was biased because the numerator (the Down's cases detected) was inflated by those Down's cases that would have spontaneously aborted and the denominator (total of cases detected and born) was similarly incorrect. Consequently, the true detection rate for nuchal fold screening should have been approximately $60 \%$ for a false positive rate of $5 \%,{ }^{69-71}$ which is comparable with most second trimester screening programmes. Furthermore, nuchal translucency can be used to screen for other major defects, especially cardiac anomalies, which may indicate that it identifies those Down's fetuses that are most likely to abort spontaneously. ${ }^{72}$ Consequently, the currently available evidence is not sufficient to identify whether nuchal fold screening, instead of biochemical screening, is a better way to spend the limited funds available.

Biochemical studies of first trimester screening have usually been retrospective so do not suffer the same fetal loss bias as the nuchal fold study. These give detection rates comparable with second trimester studies. Using the same statistical method as described above, there is therefore no evidence that first trimester biochemical screening provides superior detection. Any decision to change must be based on the evidence of the patient benefits of early screening. One difficulty that will be encountered if it is decided to introduce first trimester screening is that many women do not present to their doctor early enough for first trimester screening to be carried out. This means that it might be necessary for laboratories to offer both first and second trimester screening tests.

Finally, would it be possible to combine nuchal fold and biochemical screening? This appears to provide the best opportunity to improve detection rates. Some impressive detection rates have been quoted, but often with high false positive rates or very small samples (for example, an $87.5 \%$ detection rate for a $14 \%$ false positive rate ${ }^{61} ; 100 \%$ detection in women aged $<35$ years and $92 \%$ for women aged $>35$ years for a $5 \%$ false positive rate, although there were only six and 12 cases, respectively ${ }^{64}$; and a $76 \%$ detection rate for a $5 \%$ false positive rate $e^{65}$. One trial using stored sera from 210 Down's syndrome cases suggests that a detection rate of $89 \%$ could be achieved at a false positive rate of $5 \% .{ }^{74}$ Unfortunately, because the cases came from the UK multicen- 
tre project, ${ }^{68}$ the detection rate estimate suffers from the same flaws. Consequently, the detection rate estimate cannot be compared directly with second trimester detection rates for the same reasons as described above. Empirically, $20 \%$ of detection was excluded from the multicentre results and a similar amount could be excluded from this trial to give a $69 \%$ detection rate for a $5 \%$ false positive rate. This is in a similar range to some estimates of second trimester detection rates, and given the wide confidence intervals for detection rates, we again cannot be certain that it offers any advantages.

At present, the benefits of combined nuchal fold and biochemical screening can only be estimated from models until prospective trials have been carried out. Model based screening programmes are often contentious and attract statistical comment. ${ }^{75}$ However, it will be difficult to carry out truly prospective trials in the future because the established "standard of care" now includes prenatal diagnosis and an offer of termination.

The Royal College of Obstetricians and Gynaecologists organised a study group to consider the issue of first trimester screening. The report ${ }^{77}$ concluded that: (1) preliminary data supported the use of nuchal fold translucency screening in centres with experienced ultrasound staff who participate in an external quality assurance scheme and are subject to regular audit; (2) the combination of biochemical and ultrasonographic markers might prove superior to either marker type alone; and (3) a national screening policy should be implemented. The final verdict is yet to be decided ...

Progress towards national coordination The NSC antenatal subgroup is currently considering Down's screening and draft recommendations are soon to be published. These are rumoured to include a recommendation that a standardised risk threshold is used to determine who should be considered "high risk". It is likely that a $1: 250$ risk cut off will be chosen as the national risk threshold because this is the most commonly used. ${ }^{78}$

\section{Conclusions}

Since antenatal serum screening for Down's syndrome began in 1988 there have been a great many developments but, despite occasional calls for a national screening policy, no coordination has yet been imposed. Consequently, even when screening is performed, there may be wide differences in the risk cut offs applied and thus the detection rate. ${ }^{78}$ For example, in one village local to my laboratory, it is possible for screening samples to be sent to one centre, which has a $1: 250$ cut off, another with a $1: 150$ cut off, and another with a $1: 100$ cut off. This is confusing for patients and could be a source of litigation. The changes in other screening services, especially cervical screening and the advent of NICE (National Institute for Clinical Excellence) and CHIMP (Commission for Health Improvement) have shown that not only does national policy improve effectiveness but there is now a political wish for change. It is therefore excellent news that the NSC is to implement recommendations to ensure consistency of screening performance.

However, it is essential that the difference between Down's screening and cervical screening is recognised and acted upon. It is clear that researchers have the right to patent their findings but, equally clearly, if they are to be involved in making national policy, any potential benefit to them or their families from those patents should be known to other members of the panel. This will protect them from later allegations that their advice to the panel was subject to bias if it is to their financial benefit.

The NSC is clearly going to deal with the issue of risk thresholds but there are several other issues that are vital to ensure true parity of screening. Down's screening relies on software interpretation of results by comparison with a set of standard population parameters. Because the many studies carried out have produced a wide range of different parameters for each analyte it is possible for one set of results to generate many different risk estimates, as has been demonstrated by NEQAS studies. I believe it would be entirely rational for the NSC to define a small number of acceptable "national standard population parameter" sets, which should be regularly reviewed to take account of new developments. This parameter set would include the population mean and SD for unaffected, Down's syndrome, and trisomy 18 pregnancies for each analyte, with defined weeks of gestation for which the parameter set is valid. Some analytes, such as PAPP-A, which change throughout the period for which they are useful, might need a more complex definition, including a calculation to account for gestational age. This is one area where complete impartiality/disclosure of interests would be essential because the incorrect setting of one parameter can falsely indicate that extra screening tests are useful. ${ }^{10}$

Defining national population parameter sets would of course have a knock on effect on software. Some software packages are black boxes that have their own defined population parameters that are not accessible to the user. It would be essential for the NSC to have the authority to order software manufacturers to alter their population parameters or to specify which features make software acceptable, with loss of accreditation for screening if inappropriate software is used.

The implementation of a national screening framework would also have to include some strategy for audit. This would be easier if screening were carried out by large units because there would be less coordination required to link cytogenetic and laboratory/ ultrasonography results. The NSC may therefore consider a minimum workload rule, similar to that used for cervical cytology screening centres. As a laboratory which only processes approximately 2500 Down's samples each year, I believe that small (local) is good because we can return results in hours when 
sending samples to a large centre would take days. It may be better for a centrally funded audit programme (essentially a central, virtual laboratory) to be developed, which would collect screening results from individual laboratories (allowing comparison of risk estimate distributions against the mathematically derived theoretical distribution), collect cytogenetic reports to match with screening tests, and collect birth defect registry reports to assess false negative results.

The final task of a national audit group should be to determine whether the current practice of every centre setting its own local medians is really necessary. At present, all laboratories tend to derive their own calculation factors and may use different strategies, resulting in different MoM distributions when calculations are completed. The aggregation of data nationally would allow statistical analysis to determine whether medians could be specified for particular batches/brands of assay.

\section{Declaration}

I declare the following personal and family interests in Down's screening:

(1) Patents: none held.

(2) Research grants: none currently held. One grant for 30000 Swiss francs held in the past.

(3) Software: Downcalc, DOS based software, non-millennium compliant. Previously made available at cost varying from $£ 0$ to $£ 50$ (profit approximately £500). RiskCalc, Windows based. Software provided free of charge if for research purposes only. Seven copies sold (profit after cost of computer upgrade $£ 700$ ).

(4) Consultancies: in the past, I have acted as a paid consultant on behalf of several diagnostic companies in respect of Down's syndrome screening developments. I am not currently acting as a consultant for any company in this area (total income $£ 5000)$.

(5) Medicolegal: I have acted as a paid expert witness in one case of litigation in respect of Down's syndrome screening.

1 Wald NJ, Cuckle HS, Densem JW, et al. Maternal serum screening for Down's syndrome in early pregnancy. BMF 1988;297:883-7.

2 Dawson A, Jones G, Matharu M, et al. Serum screening for Down's syndrome: a summary of one year's experience in South Wales. Br F Obstet Gynaecol 1993;100:875-7.

3 Wald NJ, Huttly WJ, Hennessy CF. Down's syndrome screening in the UK in 1998. Lancet 1999;354:1264.

4 Sheldon T. Dutch doctors call for all pregnant women to be screened for Down's. BMF 1999;319:872

5 Mantingh A, Beekhuis JR, Kornman LH. Organisation of screening programmes: the Dutch experience. In: Grudzinskas JG, Chard T, Chapman M, et al, eds. Screening for Down's syndrome. Cambridge: University Press, 1994:23744.

6 De Graaf IM, Pajkrt E, Bilardo CM, et al. Early pregnancy screening for fetal aneuploidy with serum markers and nuchal translucency. Prenat Diagn 1999;19:458-62.

7 International Down's Syndrome Screening Group. HCG patent news. Down's screening news, January 1998. Leeds: International Down's Sydrome Screening Group.

8 Goodlin RC. Free $\beta$-protein studies need confirmation. Am F Obstet Gynecol 1991;165:779-80.

9 Seth J, Sturgeon CM, Ellis AR, et al. UKNEQAS for screening for Down's syndrome-participant survey. In ing for Down's syndrome-participant survey. In annual review. Edinburgh: UKNEQAS, 1996:A14-19.

10 Reynolds T. Screening by test combination: a statistical overview. In: Grudzinskas JG, Chard T, Chapman M, et al, eds. Screening for Down's syndrome. Cambridge: University eds. Screening for Dow
Press, 1994:47-71.
11 Macri JN, Spencer K, Garver K, et al. Maternal serum free beta hCG screening: results of studies including 480 cases f Downs syndrome. Prenat Diagn 1994;14:97-103.

12 Wierzbicki AS. Maternal serum free beta hCG screening: results of studies including 480 cases of Downs syndrome-problems with this approach. Prenat Diagn 1994;14:1093-5.

13 Ryall RG, Staples AJ, Robertson EF, et al. Improved performance in a prenatal screening programme for Down's syndrome incorporating serum free hCG subunit analyses. Prenat Diagn 1992;12:251-61.

14 Haddow JE, Palomaki GE, Knight GJ, et al. Prenatal screening for Down's syndrome with use of maternal serum markers. N Engl f Med 1992;327:588-93.

15 Herrou M, Leporrier N, Leymarie P. Screening for fetal Down syndrome with maternal serum hCG and oestriol: a prospective study. Prenat Diagn 1992;12:887.

16 Phillips OP, Elias S, Schulman LP, et al. Maternal serum screening for fetal Down's syndrome in women less than 35 years of age using alpha-fetoprotein, hCG and unconjugated estriol: a prospective 2 year study. Obstet Gynecol gated estriol:

17 Wald NJ, Kennard A, Densem JW, et al. Antenatal maternal serum screening for Down's syndrome: results of a demonstration project. BMF 1992;305:391

18 Crandall BF, Hanson FW, Keener MS, et al. Maternal serum screening for alpha-fetoprotein, unconjugated estriol and human chorionic gonadotropin between 11 and 15 weeks of pregnancy to detect fetal chromosome abnormalities. Am f Obstet Gynecol 1993;168:1864.

19 Goodburn SF, Yates JR, Raggatt PR, et al. Second trimester maternal serum screening using alpha-fetoprotein, human chorionic gonadotropin and unconjugated oestriol: experience of a regional programme. Prenat Diagn 1994;14:391402 .

20 Ganiats TG, Halverson AL, Bogart MH. Incremental cost effectiveness of incorporating oestriol evaluation in Down syndrome screening programmes. Prenat Diagn 1994;14: 527-35.

21 Kellner LH, Weiss RR, Wiener Z, et al. The advantages of using triple-marker screening for chromosomal abnormalities. Am F Obstet Gynecol 1995;172:831-6.

22 Kellner LH, Wiener Z, Weiss RR, et al. Triple marker $\alpha$-fetoprotein, unconjugated estriol, human chorionic gonadotropin) versus $\alpha$-fetoprotein plus free- $\beta$ subunit in second trimester maternal serum screening for fetal Down syndrome: a prospective comparison study. Am $\mathcal{F}$ Obstet Gynecol 1995;175:1306-9.

23 Valerio D, Aiello R, Altieri V, et al. Maternal serum screening of fetal chromosomal abnormalities by AFP, uE3, hCG and free $\beta$-HCG. Minerva Ginecol 1996;48:169-73.

24 Macri JN, Kasturi RV, Krantz DA, et al. Maternal serum Down syndrome screening: unconjugated estriol is not useful. Am $\mathcal{F}$ Obstet Gynecol 1990;162:672.

25 Amerlite Diagnostics Ltd. Down's syndrome and neural tube defects risk assessment; trial results manual - a retrospective study. Amersham: Amerlite Diagnostics, 1991

26 Macri JN, Kasturi RV, Krantz DA, et al. Sensitivity and specificity of screening for Down syndrome with alpha etoprotein, hCG unconjugated estriol and maternal age. Obstet Gynecol 1991;77:963-4.

27 Dungan JS, Phillips OP, Shulman LP, et al. Improved specificity of maternal serum screening for fetal Down syndrome by excluding uE3 level. Am f Hum Genet 1993;5(suppl):1402.

28 Crossley JA, Aitken DA, Connor JM. Second trimester unconjugated oestriol levels in maternal serum from chromosomally abnormal pregnancies using an optimized mosomally abnormal pregnancies

29 Spencer K, Coombes EJ, Mallard AS, et al. Free beta human chorionic gonadotropin in Down's syndrome screening: a multicentre study of its role compared with other biochemical markers. Annals of Clinical Chemistry 1992;29: 506-18

30 Reynolds T, John R, Spencer K. The use of unconjugated estriol in Down syndrome screening is unproven. Clin Chem 1993;39:2023-5.

31 Bartels I, Bockel B, Caesar J, et al. Risk of fetal Down's syndrome based on maternal age and varying combinations of maternal serum markers. Arch Gynecol Obstet 1994;255:57.

32 David M, Merksamer R, Israel N, et al. Unconjugated estriol as maternal serum marker for the detection of Down
syndrome pregnancies. Fetal Diagn Ther 1996;11:99-105.

33 Reynolds T, John R. A comparison of unconjugated estriol assay kits shows that expression of results as multiples of the median causes unacceptable variation in calculated Down syndrome risk factors. Clin Chem 1992;38:1888-93.

34 Dunstan F, Gray J, Nix A, et al. Detection rates and false positive rates for Down's syndrome screening: how precisely can they be estimated and what factors influence their value. Stat Med 1997;16:1481-95.

35 Macri JN, Kasturi RV, Krantz DA, et al. Maternal serum screening: free $\beta$-protein is a more effective marker than human chorionic gonadotropin. Am f Obstet Gynecol 1990; 163:1248-53.

36 Spencer K. Evaluation of an assay of the free beta-subunit of choriogonadotropin and its potential value in screening for Down's syndrome. Clin Chem 1991;37:809-14.

37 Spencer K, Macri JN. Early detection of Down's syndrome using free beta human choriogonadotropin. Ann Clin Biochem 1992;29:349-50.

38 Spencer K, Carpenter P. Prospective study of prenatal screening for Down's syndrome with free beta-human chorionic gonadotropin. BMF 1993;307:764. 
39 Wenstrom KD, Owen J, Chu DC, et al. Free $\beta$-HCG subunit versus intact hCG in Down syndrome screening. Obstet nit versus intact hCG in

40 Knight GJ, Cole LA. Measurement of choriogonadotropin free $\beta$-subunit: an alternative to choriogonadotropin in screening for fetal Down's syndrome? Clin Chem 1991;37 $779-82$.

41 Wald NJ, Densem J, Stone R, et al. The use of free $\beta$-hCG in antenatal screening for Down's syndrome. $\mathrm{Br} \mathcal{F}$ Obstet Gynaecol 1993;100:550-7

42 Wald $\mathrm{N}$, Hackshaw A. Use of free $\beta$-hCG in Down's syndrome screening. Ann Clin Biochem 1993;30:515.

43 Stone S, Henley R, John R, et al. A comparison of total and free $\beta$ HCG assays in Down syndrome screening. Prenat Diagn 1993;13:535-7.

44 Milunsky A, Nebiolo LM, Bellet D. Maternal serum screening for chromosome defects: human chorionic gonadotropin versus its free-beta subunit. Fetal Diagn Ther 1993;8: pin versus $221-4$.

45 Kardana K, Cole LA. Polypeptide nicks cause erroneous results in assays of human chorionic gonadotropin free results in assays of human chorion

46 Stevenson HP, Leslie H, Sheridan B. Serum free $\beta$-human chorionic gonadotropin concentrations increase in unseparated blood specimens. Ann Clin Biochem 1993;30:99-100.

47 Zimmermann R, Keller PJ, Huch A. Increased maternal serum free $\beta$ human chorionic gonadotropin. $\mathrm{Br} \mathcal{F}$ Obstet Gynaecol 1994;101:257-8.

48 Reynolds T. Increased maternal serum free $\beta$ human chorionic gonadotropin concentrations in Down's pregnancies: an artefactual finding? Br f Obstet Gynaecol 1994;104: 1025-6.

49 Stone SJ, Henley R. The stability of blood samples for the measurement of the free $\beta$-subunit of chorionic gonadotropin. Prenat Diagn 1995;15:95-6.

50 Sancken U, Bahner D. The effect of thermal instability of intact human chorionic gonadotropin (ihCG) on the application of its free $\beta$-subunit (free $\beta$-hCG) as a serum marker cation of its free $\beta$-subunit (free $\beta$-hCG) as a serum marker
in Down syndrome screening. Prenat Diagn 1995;15:731in 8 .

51 Beaman J, Akhtar N, Goldie DJ. Down's syndrome screening using free $\beta$-HCG: instability can significantly increase the Down's risk estimate. Ann Clin Biochem 1996:33:5259.

52 Wald NJ, Watt HC, Hackshaw AK. Integrated screening for Down's syndrome based on tests performed during the and second trimesters. N Engl F Med 1999;341:461-7.

53 Copel JA, Bahado-Singh RO. Prenatal screening for Down's syndrome - a search for the family's values [editorial]. $N$ Engl f Med 1999;341:521-2.

54 Reynolds T, Zimmermann R, Wright E. Integrated screening for Down's syndrome. N Engl f Med 1999;341: 1395-7.

55 Brizot ML, Snijders RJ, Bersinger NA, et al. Maternal serum pregnancy associated plasma protein $\mathrm{A}$ and fetal nuchal translucency thickness for the prediction of fetal trisomies in early pregnancy. Obstet Gynecol 1994;84:918-22.

56 Bersinger NA, Marguerat P, Pescia G, et al. Pregnancy associated plasma protein A (PAPP-A) measurement by highly sensitive and specific enzyme immunoassay, importance of sensitive and specific enzyme immunoassay, importance of first trimester determination

57 Wald NJ, Kennard A, Hackshaw AK. First trimester serum screening for Down's syndrome. Prenat Diagn 1995;15 $1227-40$
58 Brizot ML, Snijders RJ, Butler J, et al. Maternal serum hCG and fetal nuchal translucency thickness for the prediction of fetal trisomies in the first trim

59 Wald NJ, George L, Smith D, et al (for the International Prenatal Screening Research Group). Serum screening for Down's syndrome between 8 and 14 weeks of pregnancy. Br f Obstet Gynaecol 1996;103:407-12.

60 Wald NJ, Densem JW, George L, et al. Prenatal screening for Down's syndrome using inhibin A as a serum marker. Prenat Diagn 1996;16:143-53.

61 Scott F, Wheeler D, Sinosich M, et al. First trimester aneuploidy screening using nuchal translucency, free beta human chorionic gonadotropin and maternal age. Aust NZ f Obstet Gynaecol 1996;36:381.

62 Casals E, Fortuny A, Grudzinskas JG, et al. First trimester biochemical screening for Down syndrome with the use of PAPP-A, AFP and $\beta$-HCG. Prenat Diagn 1996;16:405-10.

63 Forest J-C, Masse J, Moutquin J-M. Screening for Down syndrome during first trimester: a prospective study using free $\beta$-human chorionic gonadotropin and pregnancy associated plasma protein A. Clin Biochem 1997;30:333-8.

64 Orlandi F, Damiani G, Hallahan TW, et al. First trimester screening for fetal aneuploidy: biochemistry and nuchal translucency. Ultrasound Obstet Gynecol 1997;10:381-6.

65 Wald NJ, Hackshaw AK. Combining ultrasound and biochemistry in first trimester screening for Down's syndrome. Prenat Diagn 1997;17:821-9.

66 Haddow JE, Palomaki GE, Knight GJ, et al. Screening of maternal serum for fetal Down's syndrome in the first trimester. N Engl f Med 1998;338:955-61.

67 Aitkin DA, Wallace EM, Crossley JA, et al. Dimeric inhibin A as a marker for Down's syndrome in early pregnancy. $N$ A as a marker for Down's syn
Engl f Med 1996;334:1231-6.

68 Snijders RJ, Noble P, Sebire N, et al. UK multicentre project on assessment of risk of trisomy 21 by maternal age and fetal nuchal translucency thickness at 10-14 weeks of gestation. Lancet 1998;351:343-6.

69 Haddow JE. Antenatal screening for Downs syndrome: where are we and where next? Lancet 1998;352:336.

70 Cuckle HS. Antenatal screening for Down's syndrome. Lancet 1998;352:1144.

71 Reynolds T. Antenatal screening for Down's syndrome. Lancet 1998;352:1145.

72 Hyett J, Perdu M, Sharland G, et al. Using fetal nuchal translucency to screen for major congenital cardiac defects at 10-14 weeks of gestation: population based cohort study. BMF 1999;318:81-5.

73 Mol BW. Down's syndrome, cardiac anomalies and nuchal translucency. BMF 1999;318:70-1.

4 Spencer K, Souter V, Tul N, et al. A screening program for trisomy 21 at $10-14$ weeks using fetal nuchal translucency, maternal serum free beta-human chorionic gonadotropin and pregnancy-associated plasma protein A. Ultrasound Obstet Gynecol 1999;13:231-7.

75 Reynolds TM, Dunstan F, Nix B, et al. Response to Wald and Hackwell. Prenat Diagn 1998;18:511-14.

76 Nicholaides KH, Snijders RJM, Cuckle HS. Response to Wald and Hackwell. Prenat Diagn 1998;18:519-20.

77 Screening for Down's syndrome in the first trimester. Grudzinskas JG, Ward RHT, eds. London: RCOG Press, 1997.

78 Reynolds T, John R. Serum screening for Down's syndrome: national policy would ensure consistency. BMF 1994;309: 1372-3. 